\title{
The Depression Level of Women Suffering Domestic Violence in Medan, Indonesia
}

\author{
Friska Gurning*, Vita Camellia, Harun Taher Parinduri, Elmeida Effendy \\ Department of Psychiatry, Faculty of Medicine, Universitas Sumatera Utara, Medan 20155, Indonesia
}

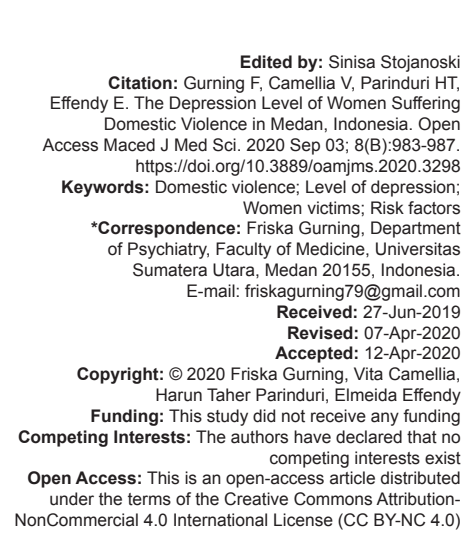

\section{Introduction}

Domestic violence is an act of violence against a person, especially adult women, which results in physical, sexual, psychological misery or suffering, and/or neglect of the household, including threats, coercion, or deprivation of liberty illegally [1], [2], [3], [4], [5]. The lifetime prevalence of domestic violence is categorized between $28 \%$ and $63 \%$ [6].

The life-long prevalence of violence against women who experience psychological or sexual violence or even both varies between $15 \%$ and $71 \%$, with the 12-month prevalence rate varies between $4 \%$ and $54 \%$. In Europe, one in 15 women with over the age of 15 has experienced domestic violence [1]. Based on data from The National Violence against Women Survey, as much as $22.1 \%$ of women during their lives have experienced physical violence received from a partner or a date. Moreover, in the United States, an estimation of 1.3 million women experience physical violence by partners annually [2]. In Indonesia, the perpetrators of violence against women are the victim's husband $(76.60 \%)$, partner, or boyfriend $(9.09 \%)$.
Domestic violence raises social problems associated with an increased risk of mental illness in women. However, only a few women victims of domestic violence dare to seek help or report the case. Women who are victims of domestic violence are prone to experience depression, anxiety, post-traumatic stress disorder, and drug abuse [7], [8], [9], [10], [11].

Some aspects that can cause domestic violence are men who commit violence to their wives are having mental disorders or diseases and stress factors such as unemployment that can cause domestic violence. Moreover, stress can lead to increase alcohol consumption and incidence of domestic violence when the perpetrator is in drunken condition. The cycle theory of violence (cycles of violence) presumes that violence is a response learned in childhood which continues to be a behavior as adults and continues to the adult generation when forming a family or community. The basis of feminist explanations describes that domestic violence is a reflection of the imbalance of power between men and women in society [2], [12].

Domestic violence has a strong relationship with depressive symptom and depression disorder such as major depression, dysthymia, or bipolar disorder. 
Depression is a mental condition characterized by symptoms of feelings of sadness, loneliness, despair, low self-esteem, and self-contempt. These signs include psychomotor retardation, agitation, and withdrawal from interpersonal relationships and are characterized by vegetative symptoms such as insomnia and anorexia [13]. There is an evidence that women who experience violence are tend to have a risk of depression [7], [8], [14]. Domestic violence also related to suicide. More than $90 \%$ of people who do commit suicide have a diagnosable psychiatric disorder, commonly depression, or substance abuse [2].

Factors related to depression in domestic violence victims are education, immigration, financial support, experiencing chronic violence [14], employment, and socioeconomic status [2]. Therefore, this study aims to determine the demographic characteristics of women who experience domestic violence and to determine the relationship between level of education, duration of experience of violence, and economic level of depression and risk factors for depression in women victims of domestic violence in Medan, Indonesia.

\section{Methods}

This is a cross-sectional study aimed to investigate depressive symptoms in women who experience domestic violence at the Psychiatric Clinic of Dr. Pirngadi General Hospital, Medan, Indonesia, from April to October 2017 [15].

\section{Inclusion criteria}

Women who experienced domestic violence, aged 18-60 years, and willing to participate were included in the study.

\section{Exclusion criteria}

Other mental disorders, history of other medical illnesses, having problems with alcohol use and psychoactive substances, being counseled, cognitive behavioral therapy, or other psychological treatments, receiving anti-depressant therapy, and other psychopharmacological therapies were excluded from the study [7].

\section{Procedure}

Subjects who met all the criteria were consecutively interviewed with ICD-10 (A1) of the Mini International Neuropsychiatric Interview [16]. The subjects were given an explanation of the purpose of the study and assured that participation was voluntary. Asigned consent form was obtained from the women who agreed to participate. Subject was asked to fill out the Indonesian version of the Beck Depression Inventory-II (BDI-II) questionnaire, a self-rating scale consisting of 21 questions. BDI-II is a tool that is frequently used in measuring the severity of depression syndrome. Scores from 0 to 13 showed minimal depression, 14-19 showed mild depression, 20-28 showed moderate depression, and 29-63 showed major depressions. The higher the feeding scores, the higher the level of depression in the subject. This questionnaire can usually be completed in 5-10 $\min$ [17], [18].

The level of the economy was assessed according to the Indonesian Central Bureau of Statistics. People's Welfare Indicator is an annual publication of the Central Bureau of Statistics that presents the level of development of Indonesian people's welfare between times and comparisons between provinces and residential areas [19]. Long experience of domestic violence is the length of time someone experiences violence in his life, which is under 1 year and over 1 year.

After all the questionnaires and the subject's personal data have been filled in completely, the questionnaire is collected and then processed and analyzed.

\section{Statistical analysis}

Data were analyzed using SPSS. To find out demographic characteristics, education level, duration of experience of violence, and economic level related to the level of depression, Chi-square test was used. The criteria for the significance of the presence or absence of a meaningful relationship are to use the value of $p<$ 0.05. Furthermore, multivariate logistic regression using educational level, long experience of violence, and economic level as risk factors of depressive symptoms in women who experience domestic violence was conducted.

\section{Results}

Based on Table 1, it is found that as many as 27 women (45.1\%) were aged between 31 and 40 years, 77 women (93.9\%) were married, 41 women (50\%) had working status, 54 women $(65.9 \%)$ had 12 years of education period, 61 women (74.4\%), experienced more than a year of violence, and 34 women (41.5\%) had moderate economic level.

Table 2 describes the most common forms of domestic violence. It is found that as many as 33 women $(40.2 \%)$ experienced neglect and psychological 
Table 1: Demographic characteristics participants

\begin{tabular}{lll}
\hline Sample characteristic & $\mathrm{n}$ & Percentage \\
\hline Age & 21 & 25.6 \\
$18-30$ & 37 & 45.1 \\
$31-40$ & 17 & 20.7 \\
$41-50$ & 7 & 8.5 \\
$\quad>50$ & 77 & 93.9 \\
Marital status & 5 & 6.1 \\
$\quad$ Married & & \\
$\quad$ Single & 41 & 50 \\
Working status & 41 & 50 \\
$\quad$ Working & & \\
$\quad$ Jobless & 28 & 34.1 \\
Educational background & 54 & 65.9 \\
$\quad>$ Senior high school & & \\
$\quad \leq$ Senior high school & 28 & 34.1 \\
Economic level & 34 & 41.5 \\
$\quad$ Low & 20 & 24.4 \\
$\quad$ Moderate & & \\
$\quad$ High & 21 & 25.6 \\
Violence period & 61 & \\
$\quad \leq 1$ year & & 23.4 \\
$\quad>1$ year & 19 & 76.8 \\
Married period & 63 & 59.8 \\
$\quad<5$ years & & 40.2 \\
$\quad>5$ years & & \\
Number of children & 39 & \\
$\quad \leq 2$ & 33 & \\
$>2$ & &
\end{tabular}

abuse, followed by 16 women experienced physical and psychological abuse (19.5\%), 15 women experienced physical, psychological and neglect (18.3\%), 8 women (9.8\%) experienced physical abuse, 7 women $(8.5 \%)$ experienced psychological abuse, and 3 women $(3.7 \%)$ experienced combination of neglect, psychological, physical, and sexual abuse.

\section{Table 2: Forms of domestic violence}

\begin{tabular}{lll}
\hline Domestic violence forms & $\mathrm{n}$ & Percentage \\
\hline Physical & 8 & 9.8 \\
Psychological & 7 & 8.5 \\
Physical, psychological & 16 & 19.5 \\
Neglect, psychological & 33 & 40.2 \\
Neglect, physical, psychological & 15 & 18.3 \\
Neglect, physical, psychological, sexual & 3 & 3.7 \\
Total & 82 & 100 \\
\hline
\end{tabular}

Table 3 describes the depression level of participants. It was found that as much as $50 \%$ of participants were reported to experience severe depression, with $29.3 \%$ and $20.7 \%$ were reported to experience moderate depression and mild depression, respectively.

Table 3: Depression level of women victim in domestic violence

\begin{tabular}{lll}
\hline Depression level (BDI-II score) & $\mathrm{n}$ & Percentage \\
\hline Mild (14-19) & 17 & 20.7 \\
Moderate (20-28) & 24 & 29.3 \\
Severe (29-63) & 41 & 50 \\
Total & 82 & 100 \\
\hline
\end{tabular}

BDI-II: Beck Depression Inventory-II.

From the 54 subjects with educational background less than senior high school, as much as $63 \%$ had a level of major depression. While for subjects with higher educational background, as much as $25 \%$

Table 4: The relationship between educational background, violence duration, and economic level with depression level

\begin{tabular}{|c|c|c|c|c|}
\hline \multirow[t]{2}{*}{ Risk factors } & \multicolumn{3}{|c|}{ Depression level } & \multirow{2}{*}{$p$} \\
\hline & Mild (\%) & Moderate (\%) & Severe $(\%)$ & \\
\hline \multicolumn{5}{|l|}{ Educational background } \\
\hline$\leq$ Senior high school & $7(13)$ & $13(24.1)$ & $34(63)$ & \multirow[t]{2}{*}{0.01} \\
\hline > Senior high school & $10(35.7)$ & $11(39.3)$ & $7(25)$ & \\
\hline \multicolumn{5}{|l|}{ Violence duration } \\
\hline$>1$ year & $5(8.2)$ & $19(31.1)$ & $37(60.7)$ & \multirow[t]{2}{*}{0.01} \\
\hline$\leq 1$ year & $12(57.1)$ & $5(23.8)$ & $4(1)$ & \\
\hline \multicolumn{5}{|l|}{ Economic level } \\
\hline Low & $3(10.7)$ & $5(17.9)$ & $20(71.4)$ & \multirow[t]{2}{*}{0.01} \\
\hline Moderate & $6(17.6)$ & $8(40)$ & $4(20)$ & \\
\hline
\end{tabular}

were showing a major depression level. The results of the analysis showed a significant relationship between the level of education and the level of depression ( $p=0.01)$ (Table 4).

Subjects who experienced more than 1 year of violence, there were as many as $60.7 \%$ having severe depression, while $19 \%$ of subjects with a level of violence for $<1$ year, experiencing severe depression. The results of the analysis indicated a significant relationship between the length of experience with violence and the level of depression ( $p=0.01)$.

As many as 20 people $(71 \%)$ of subjects with a low economic level experienced severe depression, while for subjects with a moderate economic level, 17 people $(50 \%)$ experienced severe depression. Finally, subjects with a high economic level indicated the lowest percentage of having severe depression with only of eight people $(25 \%)$. Then, the results of the analysis revealed a value of $p=0.001$

Table 5: The analysis result of depression risk factors through logistic regression

\begin{tabular}{llll}
\hline Risk factors & $\mathrm{p}$ & $\mathrm{OR}$ & $\mathrm{Cl} 95 \%$ \\
\hline Educational background & 0.022 & 3.754 & $1.205-11.692$ \\
Economic level & 0.01 & 4.436 & $1.428-13.784$ \\
Violence duration & 0.018 & 4.939 & $1.309-18.632$ \\
\hline p: signifance; ${ }^{*}$ OR: odds ratio; Cl: confidence interval & &
\end{tabular}

Using multiple logistic regression tests using the enter method, it was found that all independent variables had a significant effect $(p<0.05)$ on the level of depression (Table 5). The most dominant variable on the level of depression is the duration of violence with the highest odds ratio $(\mathrm{OR})$ value $=4.939$, suggesting that subjects who get violence for more than 1 year will be at risk of experiencing severe levels of depression compared to subjects with lesser duration of violence. The second variable that leads to major depression is the economic level with a value of $\mathrm{OR}=4.436$. This means that participants with a low economic level are at 4.436 times risk causing severe depression compared to subjects with moderate and high economic levels. The third variable that influences the occurrence of major depression is the level of education with an OR value of 3.754 , which means that participants with a low education level are tend to develop major depression at 3.754 times compared to subjects with a higher level of education.

\section{Discussion}

In this study, most common forms of domestic violence were neglected and psychological with as many as 33 people (40.2\%), followed by physical and psychological forms for 16 people (19.5\%), forms of neglect, physical and psychological with 15 people (18.3\%), physical form of eight people $(9.8 \%)$, psychological forms as many as seven people (8.5\%), and forms of neglect, psychological, 
physical, and sexual as many as three people (3.7\%). This is consistent with a study conducted by Wong et al. (2007), where more forms of psychological violence were found in women victims of domestic violence who suffered severe depression [14]. Furthermore, this study is in accordance with a study conducted by Hegarty et al. (2000) where the most common form of violence was a combination of two forms of violence [20].

The results of the analysis show a significant relationship between the level of education and the level of depression $(p=0.01)$. This study is in accordance with Wong et al. (2007), discovered that women victims of domestic violence with low education were more easily depressed than those with higher education. This is because victims with low education have fewer opportunities to get jobs or obtain economic sufficiency or be free from poverty so that they are economically dependent on their partners. Women victims of domestic violence with low education are lack of knowledge about domestic violence, resulting them to be a lack in receiving information about how to protect them from the violence. This situation creates feelings of despair and results in depression [14].

In this study, from 61 subjects who experienced violence for more than 1 year, there were 37 people $(60.7 \%)$ which are categorized to have a level of severe depression. While for subjects who experienced violence for $<1$ year, it was only four people (19\%) experiencing level of severe depression. The results of the analysis revealed a significant relationship between the length of violence experience and the level of depression $(p=0.001)$. A similar study toward this condition has been reported by Trevillion et al. (2012), discovered that depression in victims of related violence has long experienced violence. This might be explained with the longer a person experiences violence, the higher the level of depression they will possess [21]. Therefore, women who are victims of domestic violence who experience long-term violence tend to experience depression.

Based on economic level, a significant relationship between economic level and depression level was found with a value of $p=0.001$. This study is in accordance with a study conducted by Ali et al. (2009), stated where victims of domestic violence with low economic levels or low income resulted in a higher level of depression [22]. Moreover, Hegarty et al. (2000) reported that depression in women who experienced more violence was found at low-income categorization [20]. Low economic levels associated with low income and unemployment (not working) limits the women victims of domestic violence to obtain social support and health services. This causes victims to become economically dependent on the perpetrators of violence.

On the other hand, there are plenty other factors that cause depression besides those that have not been discussed in this study such as employment status, age, number of children, history of psychoactive substance use, history related to legal problems, history of experiencing childhood violence, and family or social support. However, the most factors that can lead to depression are violence duration, economic level, and educational background, respectively.

The limitation of this study is not to compare the level of depression with the types of violence experienced by victims of domestic violence, where this can affect the level of depression in women victims of domestic violence. However, the study of the relationship between depression levels and demographic characteristics, long experience of violence, and economic level in Medan, Indonesia, has never been studied.

\section{Conclusion}

This study shows a significant relationship between education level, duration of violence, and economic level with the level of depression in women victims of domestic violence. Therefore, it is expected that clinicians and related parties will screen and provide attention and psychosocial interventions to prevent mental disorders, especially depression, in victims of domestic violence.

\section{Acknowledgment}

The authors would like to thank Dr. Pirngadi General Hospital, Medan, Indonesia, for facilitating the research.

\section{References}

1. Showalter K. Women's employment and domestic violence: A review of the literature. Aggress Violent Behav. 2016;31:37-47. https://doi.org/10.1016/j.avb.2016.06.017

2. Lockton D. Domestic Violence. London: Cavendish Publishing Limited; 1997.

3. Davis RL. Domestic Violence Intervention, Prevention, Policies, and Solutions. Florida: CRC Press; 2008

4. Kavak F, Aktürk Ü, Özdemir A, Gültekin A. The relationship between domestic violence against women and suicide risk. Arch Psychiatr Nurs. 2018;32(4):574-9. https://doi.org/10.1016/j. apnu.2018.03.016

PMid:30029750

5. Boughima FA, Razine R, Benyaich $H$, Mrabet M. The profile of women victims of domestic violence in Morocco. Rev Méd Légale. 2018;9:96-102. https://doi.org/10.1016/j.medleg.2018.05.002

6. Lawrence S, Chau M, Lennon MC. Depression, Substance Abuse, and Domestic Violence. Columbia University: The National Center for Children in Poverty; 2004. 
7. Ferrari G, Agnew-Davies R, Bailey J, Howard L, Howarth E, Peters TJ, et al. Domestic violence and mental health: A crosssectional survey of women seeking help from domestic violence support services. Glob Health Action. 2016;9:29890. https://doi. org/10.3402/gha.v9.29890

8. Warshaw C, Barnes H. Domestic Violence, Mental Health and Trauma. Chicago, IL: Wacker Drive, Suite; 2003.

9. Coston BM. Disability, sexual orientation, and the mental health outcomes of intimate partner violence: A comparative study of women in the U.S. Disabil Health J. 2019;12(2):164-70. https:// doi.org/10.1016/j.dhjo.2018.11.002 PMid:30448101

10. Russo A, Reginelli A, Pignatiello M, Cioce F, Mazzei G, Fabozzi $O$, et al. Imaging of violence against the elderly and the women. Semin Ultrasound. 2019;40:18-24. https://doi. org/10.1053/j.sult.2018.10.004

11. Çelik AS, Kırca N. Prevalence and risk factors for domestic violence against infertile women in a Turkish setting. Eur J Obstet Gynecol Reprod Biol. 2018;231:111-6. https://doi. org/10.1016/j.ejogrb.2018.10.032

PMid:30342312

12. Markovik M, Peshevska DJ. Gender as individual risk factor for elderly abuse: Findings from first national prevalence study in Macedonia. Open Access Maced J Med Sci. 2014;2:373. https://doi.org/10.3889/oamjms.2014.064

13. Sadock BJ, Sadock VA, Ruiz P. Kaplan and Sadock's Comprehensive Textbook of Psychiatry. $10^{\text {th }}$ ed. New York: Lippincott Williams and Wilkins; 2017.

14. Wong JY, Tiwari A, Fong DY. Depression among women experiencing intimate partner violence in chinese community. Nurs Res. 2011;60:58-65. https://doi.org/10.1097/ nnr.0b013e3182002a7c

PMid:21127447

15. Dahlan MS. Langkah-Langkah Membuat Proposal Penelitian Bidang Kedokteran dan Kesehatan. $2^{\text {nd }}$ ed. Jakarta: Sagung

\section{Seto; 2014.}

16. van Vliet IM, de Beurs E. The MINI-International Neuropsychiatric Interview. A brief structured diagnostic psychiatric interview for DSM-IV en ICD-10 psychiatric disorders. Tijdschr Psychiatr 2007;49:393-7.

PMid:17614093

17. Arnau RC, Meagher MW, Norris MP, Bramson R. Psychometric evaluation of the beck depression inventory-II with primary care medical patients. Health Psychol. 2001;20(2):112-9. https://doi. org/10.1037/0278-6133.20.2.112

PMid: 11315728

18. Ginting H, Näring G, van der Veld WM, Srisayekti W, Becker ES. Validating the beck depression inventory-II in Indonesia's general population and coronary heart disease patients. Int $\mathrm{J}$ Clin Heal Psychol. 2013;13:235-42. https://doi.org/10.1016/ s1697-2600(13)70028-0

19. Statistik BP. Statistik Kesejahteraan Rakyat; 2018. Available from: https://www.bps.go.id/publication/2018/11/26/ 81ede2d56698c07d510f6983/ statistik-kesejahteraanrakyat-2018.html. [Last accessed on 2019 Jun 25].

20. Hegarty K, Gunn J, Chondros P, Small R. Association between depression and abuse by partners of women attending general practice: Descriptive, cross sectional survey. BMJ. 2004;328(7440):621-4. https://doi.org/10.1136/bmj.328.7440.621 PMid:15016694

21. Trevillion K, Oram S, Feder G, Howard LM. Experiences of domestic violence and mental disorders: A systematic review and meta-analysis. PLoS One. 2012;7(12):e51740. https://doi. org/10.1371/journal.pone.0051740 PMid:23300562

22. Ali FA, Israr SM, Ali BS, Janjua NZ. Association of various reproductive rights, domestic violence and marital rape with depression among Pakistani women. BMC Psychiatry. 2009;9:77. https://doi.org/10.1186/1471-244x-9-77

PMid: 19951410 